\title{
Simulation-Based Energy Usage Profiling of Machine Tool at the Component Level
}

\author{
Wonkyun Lee', Chan-Young Lee', and Byung-Kwon Min'" \\ 1 Department of Mechanical Engineering, Yonsei University, 50 Yonsei-ro, Seodaemun-gu, Seoul, South Korea, 120-749 \\ \# Corresponding Author / E-mail: bkmin@yonsei.ac.kr, TEL: +82-2-2123-5813, FAX: +82-2-364-6769
}

KEYWORDS: Energy efficient manufacturing, Virtual machine tool, Machine tool simulation, Energy consumption

\begin{abstract}
This paper describes a virtual machine tool (VMT) that can be used to estimate the energy consumption of machine tools at the component level. The VMT was designed by focusing on accurately estimating the dynamic behavior and energy consumption of the servo system, which has a major impact on the total energy consumption. Simulation models of the controller and feed drive were constructed. The energy consumption levels of the feed drive components were analyzed theoretically and integrated into the model. An experimental setup of the servo system incorporating a hardware-in-the-loop simulation testbed was constructed to evaluate the proposed model. Simplified models of the spindle, auxiliary units, and cutting dynamics were included in the VMT to estimate the energy consumption of the machine tool components during milling. This simulation technique was used to quantify the effects of machine tool design modification and process control and to simulate the relationship between the specific energy consumption and the material removal rate in order to reduce the overall energy consumption.
\end{abstract}

Manuscript received: May 12, 2014 / Accepted: May 22, 2014 (Invited Paper)

\section{Introduction}

Recently, enhancing the energy efficiency of machine tools has become an important issue given the emphasis on green manufacturing. ${ }^{1-3}$ Various studies have analyzed machine tools with the goal of reducing their energy consumption. As a starting point, techniques for monitoring and analyzing the energy consumption of machine tools have been described. ${ }^{46}$ For example, Kara et al. ${ }^{4}$ summarized the techniques and challenges of electricity monitoring as well as metering systems for gathering energy consumption data for manufacturing systems. Behrendt et $\mathrm{al}^{5}{ }^{5}$ proposed a method for monitoring energy consumption involving detailed experimental procedures using standardized workpieces. The energy consumption levels of different types of machine tools were compared using their method.

Approaches for energy efficiency enhancement can be classified according to whether they apply to machine tool design or machining processes. The first approach improves the energy efficiency by modifying the machine tool design considering the required performance. ${ }^{7,8}$ For example, Uhlmann et al. $^{7}$ proposed a design concept for a lightweight machine tool feed drive design without compromising positioning accuracy. A feed drive model containing a
Kalman filter-based dislocation compensator was used to estimate the accuracy of the modified design. The second approach enhances energy efficiency by optimizing the machining process. Process control techniques to minimize lost energy streams by reducing the idling time and automating the auxiliary units have been proposed. ${ }^{9,10}$ Additionally, methods have been presented to reduce energy consumption by optimizing the process parameters based on experimental data ${ }^{10-13}$ For example, Mori et al. ${ }^{10}$ investigated the effects of machining conditions (e.g., cutting speed, feed per tooth, and cutting depth) on energy consumption during drilling and milling, and Diaz et al. ${ }^{11}$ proposed a strategy to reduce the energy consumption of milling machines by characterizing the specific energy consumption (SEC) of the machine tool as a function of the material removal rate (MRR).

The proposed methods that optimize the process parameters based on experimental data can effectively reduce energy consumption, but they are difficult to use when the machine tool design and machining conditions (e.g., workpiece material, tool diameter, etc.) are modified. Herrmann et al. ${ }^{14}$ proposed an energy-oriented simulation model of the manufacturing system to overcome this limitation. The energy consumption of the machine tools was estimated to plan and control the manufacturing system. However, the energy consumption of individual machine tool components (e.g., feed drive components, spindle motor, 
etc.) was difficult to estimate because the study focused on systemlevel energy consumption. Energy consumption data for machine tool components can be used to reduce energy consumption by optimizing the process parameters or modifying the machine tool design.

This paper presents a simulation-based framework to estimate the energy consumption of a machine tool at the component level. A virtual machine tool (VMT) comprising machine tool component models for the servo system and auxiliary units was designed. The VMT focused on accurately estimating the dynamic behavior and energy consumption of the servo system, which plays an important role in determining the total energy consumption of the machine tool. In a milling machine, more than $30 \%$ of the fixed power, defined as the power demand of all activated machine components to ensure operational readiness of the machine tool, is required to operate the servo system. ${ }^{9}$ This proportion increases during machining because the cutting force acts as a disturbance on the feed drives and spindle motor. Furthermore, the dynamic behavior of the servo system is one of the most crucial factors in determining the energy consumption of a machine tool because the machining time dominates energy consumption.

Simulation models of the controller and ball screw-driven feed drive were constructed. ${ }^{15}$ The mechanical and electrical energy consumptions of the feed drive parts (e.g., motor, ball screw, and linear motion (LM) guide) were analyzed theoretically and integrated into the model to estimate the energy consumption accurately. The spindle motor was modeled in a manner similar to the servo system motor.

A servo system testbed consisting of the controller and the specially designed feed drive was constructed to identify the necessary parameters and evaluate the proposed model. A variety of sensors were installed to measure the energy consumption of each feed drive component. The model parameters were then identified by fitting the experimentally measured data. A hardware-in-the-loop (HIL) simulation method was employed to verify the accuracy of the feed drive model.

A dynamic milling model ${ }^{16}$ was integrated into the servo system model to estimate the cutting forces that affect the feed drives and spindles. These simulation models were used for profiling the energy usage of a milling machine during straight channel machining. The effects of machine tool design modifications and the process control on the energy consumption were then profiled using the VMT. Furthermore, the relationship between the SEC and the MRR was analyzed to verify that the proposed VMT could be used to reduce the energy consumption of a machine tool.

\section{Design of the Servo System Model}

This section describes the procedures used to design the servo system (i.e., controller and feed drive) model to estimate the dynamic behavior and energy consumption of a machine tool.

The simulation model for the controller comprising the tool-path generator and control algorithm was constructed based on the information released in the user manual of a commercial controller.

Fig. 1 shows the configuration of the controller model. The tool-path generator consisted of the G-code interpreter, interpolator, and velocity profiler. MATLAB Simulink was used to model the control algorithm, which included the position, velocity, and current control loop.
The dynamic model of the feed drive was derived as follows:

$$
\left[\left(J_{M}+J_{B}\right)\left(\frac{2 \pi}{p_{b}}\right)^{2}+M_{L}\right] \ddot{x}+B_{M}\left(\frac{2 \pi}{p_{b}}\right)^{2} \dot{x}=u-F_{M}-F_{B}-F_{L}-F_{C} .
$$

$J_{M}$ and $J_{B}$ represent the mass moment of inertia of the motor and ball screw. $M_{L}, B_{M}, p_{b}, x, u$ and $F_{C}$ denote the mass of table including LM blocks, motor damping, ball screw lead, table position, input force and cutting force, respectively. $F_{M}, F_{B}$ and $F_{L}$ represent the friction force generated at the motor, ball screw and LM guide, respectively. Only the Coulomb friction was used to describe the motor friction because the motor has a simple friction behavior. For the ball screw and LM guide, otherwise, a LuGre model containing both sliding and pre-sliding friction was employed to estimate the frictional forces because of their complex friction behavior. The friction of the ball screw is derived as follows: ${ }^{17}$

$$
F_{B}=\sigma_{B 0} z_{B}+\sigma_{B 1}\left(\dot{x}-\sigma_{B 0} \frac{|\dot{x}|}{f_{B}(\dot{x})} z_{B}\right)+\mu_{B} \dot{x},
$$

where $\sigma_{B O}, \sigma_{B I}$ and $z_{B}$ represent average stiffness, damping, and deflection of the contact asperities of the ball screw, respectively. $\mu_{B}$ denotes the viscous friction coefficient. $f_{B}(\dot{x})$ is a function of the nonlinearities of the velocity-friction characteristics of the ball screw that is expressed as

$$
f_{B}(\dot{x})=F_{B C}+\left(F_{B S}-F_{B C}\right) \exp \left(\frac{|\dot{\mid}|}{v_{B}}\right),
$$

where $F_{B C}, F_{B S}$ and $v_{B}$ denote the Coulomb friction, viscous friction and Stribeck velocity of the ball screw, respectively. Friction of the LM guide is derived in a manner similar to the ball screw.

The cutting forces in the $x$ - and $y$-directions and the cutting torques acting on the spindle were calculated using a dynamic model for orthogonal cutting. ${ }^{16}$ The derived cutting forces and torques were applied to the servo system model.

Table 1 lists the composition and power losses of the feed drive system

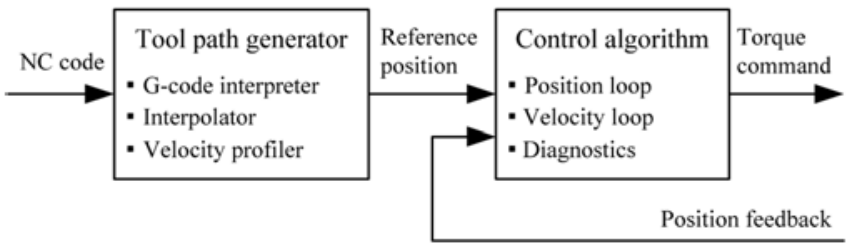

\begin{tabular}{|c|c|c|c|}
\hline Component & Losses & Factors & Output \\
\hline Motor drive & - & - & Driving power \\
\hline \multirow{2}{*}{ Motor } & $\begin{array}{l}\text { Electrical } \\
\text { loss }\left(P_{M 1}\right)\end{array}$ & $\begin{array}{c}\text { Idling loss } \\
\text { Copper loss } \\
\text { Iron loss }\end{array}$ & $\begin{array}{l}\text { Driving torque of } \\
\text { the motor }\end{array}$ \\
\hline & $\begin{array}{c}\text { Mechanical loss } \\
\left(P_{M 2}\right)\end{array}$ & $\begin{array}{l}\text { Inertial force } \\
\text { Damping force } \\
\text { Friction force }\end{array}$ & $\begin{array}{l}\text { Torque used to } \\
\text { drive the ball } \\
\text { screw }\end{array}$ \\
\hline Ball screw & $\begin{array}{c}\text { Mechanical loss } \\
\left(P_{B}\right)\end{array}$ & $\begin{array}{l}\text { Inertial force } \\
\text { Friction force }\end{array}$ & $\begin{array}{c}\text { Force used to drive } \\
\text { the table }\end{array}$ \\
\hline $\begin{array}{l}\text { Table with } \\
\text { LM guide }\end{array}$ & $\begin{array}{c}\text { Mechanical loss } \\
\left(P_{L}\right)\end{array}$ & $\begin{array}{l}\text { Inertial force } \\
\text { Friction force }\end{array}$ & Table position \\
\hline
\end{tabular}

Fig. 1 Configuration of the controller model

Table 1 Composition and power losses of the feed drive system 
during operation. The energy consumption can be calculated by integrating the power losses of the feed drive system. The power losses of the motor are composed of electrical loss $\left(P_{M}\right)$ and mechanical loss $\left(P_{M 2}\right)$, which were considered separately to improve the estimation accuracy. ${ }^{18}$

The electrical losses of the motor are composed of the idling loss $\left(P_{I}\right)$, copper loss $\left(P_{C}\right)$, and iron loss $\left(P_{F}\right) \cdot{ }^{18}$ The copper loss can be expressed as

$$
P_{C}=k_{C} P_{M 1},
$$

where $k_{C}$ represents the copper loss coefficient. The iron loss $\left(P_{F}\right)$, composed of the hysteresis loss and eddy-current loss, can be expressed as a function of the table velocity $(\dot{x})$ :

$$
P_{F}=k_{H} \dot{x}+k_{E} \dot{x}^{2},
$$

where $k_{H}$ and $k_{E}$ denote the coefficients of hysteresis loss and eddycurrent loss, respectively. From Eqs. (4) and (5), the total electrical loss can be expressed as a function of the table velocity as follows:

$$
P_{M 1}=\frac{P_{I}}{1-k_{C}}+\frac{k_{H}}{1-k_{C}} \dot{x}+\frac{k_{E}}{1-k_{C}} \dot{x}^{2} .
$$

This function can be simplified to

$$
P_{M 1}=k_{e 0}+k_{e 1} \dot{x}+k_{e 2} \dot{x}^{2},
$$

where $k_{e 0}, k_{e l}$, and $k_{e 2}$ are the electrical loss coefficients derived experimentally. The mechanical loss of the motor was calculated as the product of the forces required to drive the motor (e.g., inertial, damping, and frictional forces) and the table velocity:

$$
P_{M 2}=\left[J_{M}\left(\frac{2 \pi}{p_{b}}\right)^{2} \ddot{x}+B_{M}\left(\frac{2 \pi}{p_{b}}\right)^{2} \dot{x}+F_{M}\right] \dot{x}
$$

The power loss of the ball screw $\left(P_{B}\right)$ and the LM guide $\left(P_{L}\right)$ were calculated similarly as follows:

$$
\begin{gathered}
P_{B}=\left[J_{B}\left(\frac{2 \pi}{p_{b}}\right)^{2} \ddot{x}+F_{B}\right] \dot{x}, \\
P_{L}=\left(M_{L} \ddot{x}+F_{L}\right) \dot{x} .
\end{gathered}
$$

\section{Identification and Verification of the Servo System Model}

Although most of the servo system model parameters (e.g., mass moment of inertia and mass) are available from datasheets, some of the motor model parameters (e.g., damping, friction, and electrical loss coefficients) and the friction parameters need to be identified experimentally. An experimental setup of the servo system was used to identify these parameters and verify the proposed model.

\subsection{Experimental Setup}

Fig. 2 shows a schematic diagram and a photograph of the experimental setup. The 150 -mm-stroke feed drive was driven using a permanent magnet synchronous motor (SGMAV, Yaskawa). The feed drive was equipped with a ball screw (BNK1205, THK), which had a diameter of $12 \mathrm{~mm}$ and a pitch of $5 \mathrm{~mm}$, and an LM guide (SSR20XW, THK). Urea-based grease (AFA, THK) with a dynamic viscosity of about $20 \mathrm{~mm}^{2} / \mathrm{s}$ was used for the ball screw and the LM guide lubrication. A controller (Turbo PMAC, Delta Tau) was used to control the feed drive testbed.

An alternating current (AC) power meter (WT333, Yokogawa), rotary torque sensor (4503A, Kistler) and a bi-directional force sensor (9217A, Kistler) were installed to measure the power losses of the motor, ball screw, and LM guide separately. As shown in Table 1, the electrical loss of the motor can be derived by subtracting the mechanical power required to drive the motor from that measured using the $\mathrm{AC}$ power meter as

$$
P_{M 1}=P_{t}-2 \pi \dot{x} T_{C} / p_{b},
$$

where $P_{t}$ and $T_{C}$ denote the driving power and torque command, respectively. Motor drive controls the current to maintain the driving torque of the motor same as the torque command. The mechanical loss of the motor was obtained using the equivalent force to drive the motor itself as follows:

$$
P_{M 2}=2 \pi \dot{x}\left(T_{C}-T_{l}\right) / p_{b},
$$

where $T_{l}$ represents the torque used to drive the ball screw that was measured using the rotary torque sensor installed between the motor shaft and the ball screw. The mechanical loss of the ball screw was derived as

$$
P_{B}=\dot{x}\left(2 \pi T_{l} / p_{b}-F_{l}\right),
$$

(a)

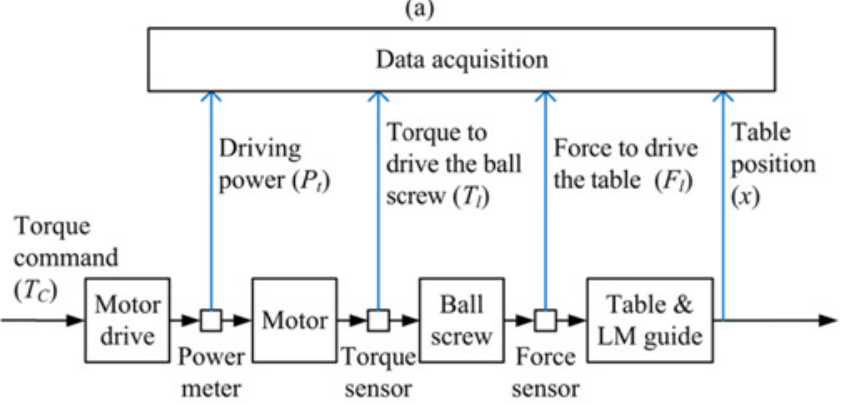

(b)

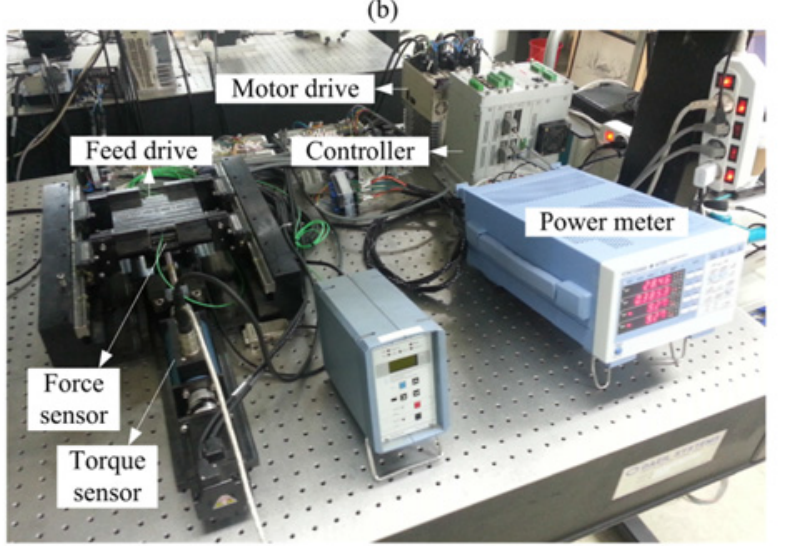

Fig. 2 Experimental setup of the servo system: (a) schematic diagram and (b) photograph 
where $F_{l}$ denotes the force used to drive the table and LM blocks that was measured using the bi-directional force sensor installed between the nut and the table. The mechanical loss of the LM guide was obtained as

$$
P_{L}=F_{p} \dot{x}
$$

The signals from the torque and force sensors were captured using a 16-bit analog-to-digital (A/D) converter with a sampling rate of $1 \mathrm{kHz}$. The driving power of the motor was captured using a power meter with a sampling rate of $10 \mathrm{~Hz}$. The power losses of the feed drive components were calculated from the experimentally measured signals using Eqs. (11-14).

\subsection{Parameter Identification}

The electrical loss coefficients $\left(k_{e 0}, k_{e l}\right.$, and $\left.k_{e 2}\right)$ were obtained by fitting the experimentally measured electrical loss-velocity curve. The dynamic model parameters of the motor, such as the damping coefficient and Coulomb friction, were determined by fitting the equivalent force to drive the motor itself. The friction model parameters were identified using a genetic algorithm-based parameter optimization method. First, the sliding parameters $\left(F_{C}, F_{S}, v_{s}, \mu_{0}\right)$ were identified using the experimentally obtained Stribeck curve. Second, the pre-sliding parameters $\left(\sigma_{0}, \sigma_{1}\right)$ were identified using the static friction parameters and the measured hysteresis curve. Some model parameters were identified individually according to the direction of the motion to improve the model accuracy. MATLAB Genetic Algorithm Toolbox was used for these tasks. Identified servo system model parameters are summarized in Table 2.

\subsection{Verification of the Servo System Model}

Fig. 3 shows the configuration of the HIL simulation used to evaluate the proposed feed drive model. The command voltage (torque command) generated at the controller was transmitted to the feed drive model using a real-time computer (ds1103, dSPACE).

Table 2 Servo system model parameters

\begin{tabular}{|c|c|c|c|c|}
\hline \multirow{2}{*}{ Component } & \multirow{2}{*}{ Symbols } & \multicolumn{2}{|c|}{ Values } & \multirow{2}{*}{ Units } \\
\hline & & Positive dir. & Negative dir. & \\
\hline \multirow{6}{*}{ Motor } & $J_{M}$ & \multicolumn{2}{|c|}{$4.0 \times 10^{-5}$} & $\mathrm{~kg} \mathrm{~m}^{2}$ \\
\hline & $B_{M}$ & $4.8 \times 10^{4}$ & $3.3 \times 10^{-4}$ & $\mathrm{Nms}$ \\
\hline & $F_{M}$ & 36.5 & 16.2 & $\mathrm{~N}$ \\
\hline & $k_{e 2}$ & 1370 & 1610 & $\mathrm{~W} \mathrm{~s}^{2} / \mathrm{m}^{2}$ \\
\hline & $k_{e 1}$ & 2.1 & 18.1 & $\mathrm{~W} \mathrm{~s} / \mathrm{m}$ \\
\hline & $k_{e 0}$ & \multicolumn{2}{|c|}{0.25} & $\mathrm{~W}$ \\
\hline \multirow{7}{*}{ Ball screw } & $J_{B}$ & \multicolumn{2}{|c|}{$1.5 \times 10^{-5}$} & $\mathrm{~kg} \mathrm{~m}^{2}$ \\
\hline & $F_{C B}$ & 69.8 & 64.6 & $\mathrm{~N}$ \\
\hline & $F_{S B}$ & 82.0 & 82.9 & $\mathrm{~N}$ \\
\hline & $v_{B}$ & $9.4 \times 10^{4}$ & $7.5 \times 10^{-4}$ & $\mathrm{~m} / \mathrm{s}$ \\
\hline & $\mu_{B}$ & $2.2 \times 10^{3}$ & $2.0 \times 10^{3}$ & $\mathrm{~N} \mathrm{~s} / \mathrm{m}$ \\
\hline & $\sigma_{B 0}$ & \multicolumn{2}{|c|}{$5.08 \times 10^{7}$} & $\mathrm{~N} / \mathrm{m}$ \\
\hline & $\sigma_{B 1}$ & \multicolumn{2}{|c|}{7706} & $\mathrm{~N} \mathrm{~s} / \mathrm{m}$ \\
\hline \multirow{7}{*}{$\begin{array}{l}\text { Table with } \\
\text { LM guide }\end{array}$} & $M_{L}$ & \multicolumn{2}{|c|}{4} & $\mathrm{~kg}$ \\
\hline & $F_{C L}$ & 5.2 & 5.4 & $\mathrm{~N}$ \\
\hline & $F_{S L}$ & 10.4 & 9.1 & $\mathrm{~N}$ \\
\hline & $v_{L}$ & $2.7 \times 10^{-3}$ & $3.3 \times 10^{-3}$ & $\mathrm{~m} / \mathrm{s}$ \\
\hline & $\mu_{L}$ & 59.8 & 55.8 & $\mathrm{~N} \mathrm{~s} / \mathrm{m}$ \\
\hline & $\sigma_{L 0}$ & \multicolumn{2}{|c|}{$5.09 \times 10^{5}$} & $\mathrm{~N} / \mathrm{m}$ \\
\hline & $\sigma_{L 1}$ & \multicolumn{2}{|c|}{1222} & $\mathrm{~N} \mathrm{~s} / \mathrm{m}$ \\
\hline
\end{tabular}

The dynamic behavior of the feed drive was simulated and transmitted to the controller in the form of encoder signals. ${ }^{19,20}$ The accuracy of the feed drive model was demonstrated by comparing the dynamic behavior of the feed drive with the HIL simulation result. Fig. 4 compares the contours and tracking errors of the feed drive testbed and the HIL simulation. The peak and root mean squared (RMS) values of the errors are listed in Table 3.

To verify the accuracy of the energy consumption estimated using the proposed servo system model, the power losses of the feed drive components were estimated and compared with the experimentally measured data. Fig. 5 shows the measured and estimated power losses of the feed drive components during reciprocal motion. Square and sinusoidal wave velocity profiles were used for the experiments. The estimation accuracy of the motor electrical loss decreased when the direction of motion was changed because the sampling frequency of the power meter was inadequate to measure the driving power of motor precisely. Table 4 lists the energy consumption levels of the feed drive components as calculated by integrating their power losses. The accuracy of the energy consumption estimates was greater than $84 \%$ for each feed drive component. The established servo system model was then integrated into the VMT.

\section{Energy Usage Profiling using the VMT}

Energy usage profiling, which consisted of an analysis of the energy consumption of the machine tool components during operation, was performed using the VMT. Fig. 6 shows the tool path and the machining

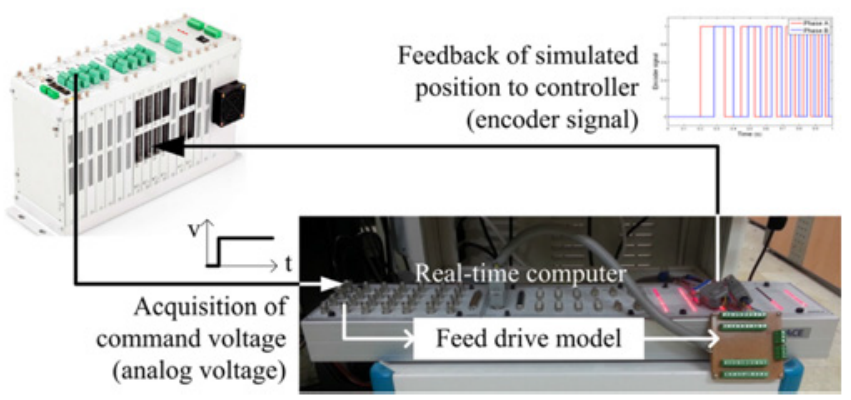

Fig. 3 Configuration of the HIL simulation
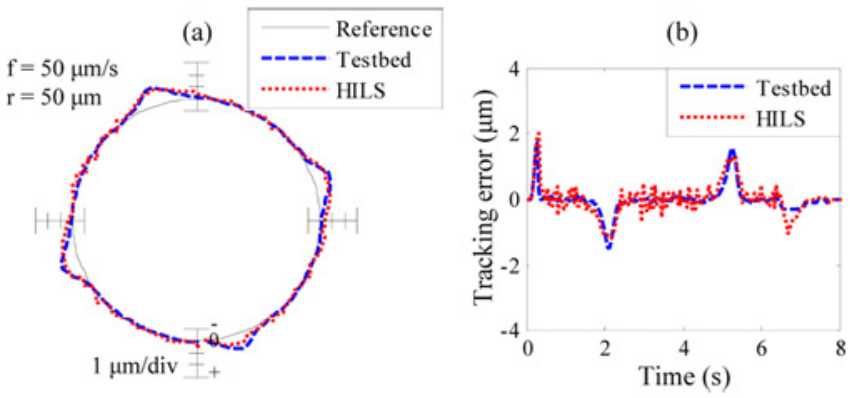

Fig. 4 Comparison of the experimentally measured (testbed) and estimated (HILS) (a) contours and (b) tracking errors

Table 3 Comparison of the contour and tracking errors

\begin{tabular}{ccccc}
\hline & \multicolumn{2}{c}{ Contour error $(\mu \mathrm{m})$} & \multicolumn{2}{c}{ Tracking error $(\mu \mathrm{m})$} \\
\cline { 2 - 5 } & Peak & RMS & Peak & RMS \\
\hline Testbed & 1.50 & 0.48 & 1.73 & 0.39 \\
\hline HIL simulation & 1.31 & 0.52 & 2.01 & 0.47 \\
\hline
\end{tabular}


conditions. A straight channel was machined using a flat-end mill operating at 3,000 RPM.

The simulation models for the spindle motor and the auxiliary units

Table 4 Energy consumption (J) of the feed drive components

\begin{tabular}{ccccc}
\hline \multirow{2}{*}{ Components } & \multicolumn{2}{c}{ Triangular wave } & \multicolumn{2}{c}{ Sinusoidal wave } \\
\cline { 2 - 5 } & Measured & Estimated & Measured & Estimated \\
\hline Motor $\left(P_{M 1}\right)$ & 19.84 & 16.80 & 20.37 & 17.84 \\
\hline Motor $\left(P_{M 2}\right)$ & 10.66 & 9.19 & 10.11 & 8.48 \\
\hline Ball screw & 33.36 & 32.25 & 31.59 & 30.56 \\
\hline LM guide & 1.83 & 1.94 & 1.81 & 1.93 \\
\hline Total & 64.84 & 60.18 & 59.57 & 58.65 \\
\hline
\end{tabular}
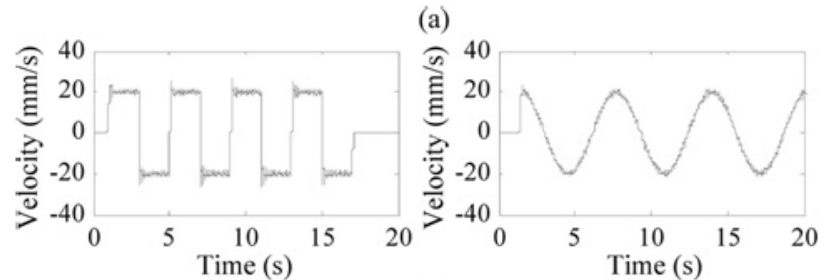

(b)
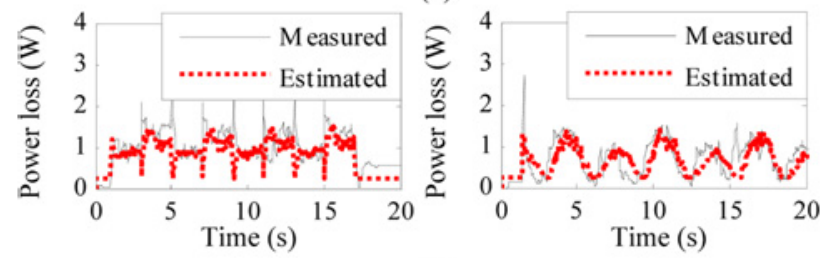

(c)
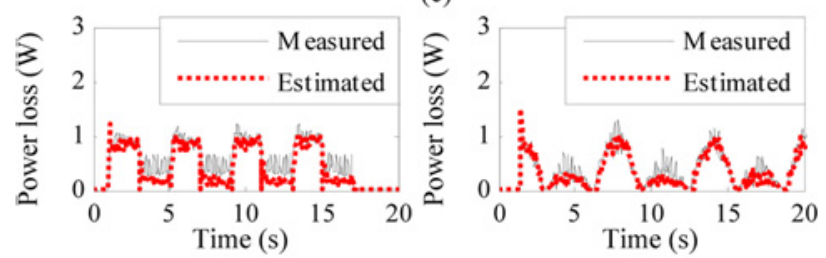

(d)
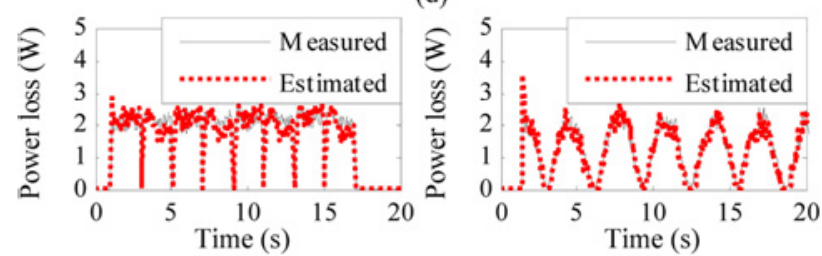

(e)
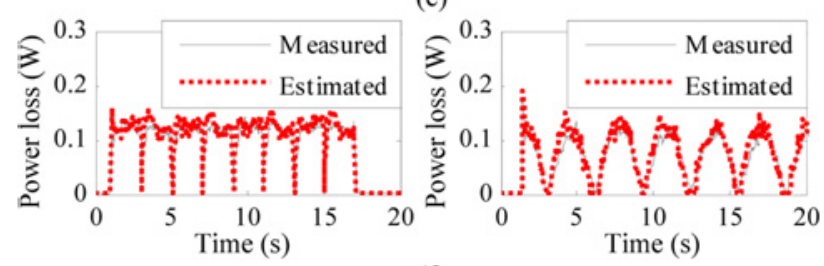

(f)
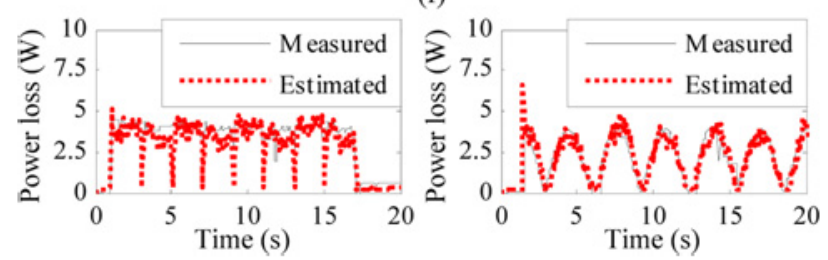

Fig. 5 Measured and estimated losses of the feed drive components during reciprocal motion with square (left) and sinusoidal (right) wave velocity profiles: (a) table velocity, (b) electrical loss of the motor, mechanical loss of the (c) motor, (d) ball screw, and (e) LM guide, and (f) total power loss of the feed drive (e.g., lubricant pump, controller) were constructed based on the specifications of commercial parts considering the size and driving power of the servo system. The operating power of the lubricant pump and controller was assumed to be $10 \mathrm{~W}$ and $15 \mathrm{~W}$, respectively.

Fig. 7 shows the simulation results of the servo system dynamics. The position and cutting forces of the $x y$ table with its contour errors were estimated. The machining accuracy and machining time were then estimated from the simulation results. Contour errors occurred at the corners of the tool path. The errors generated at the first and second corners (during material removal) were greater but saturated more quickly than the errors generated at the third and fourth peaks due to the effect of the cutting force.

Fig. 8 shows the power losses and energy consumptions of individual machine tool components simulated using the VMT. The loss of the feed drive and the spindle motor accounted for $30.5 \%$ of the total loss before the machining started. During machining, the proportion increased to $34.7 \%$ due to the effect of the cutting forces. A total of $1.04 \mathrm{~kJ}$ of energy was consumed during machining.

Techniques to reduce the energy consumption of machine tools, such as machine tool design modification and process control, were then employed. The spindle motor (spindle motor A) was downsized (spindle motor B) because the rated torque of the motor was $0.3 \mathrm{Nm}$, whereas the

Workpiece: Al

- size: $30 \times 30 \times 2(\mathrm{~mm})$

Tool: WC

- diameter: $1 \mathrm{~mm}$

- number of flutes: 4

Machining conditions - spindle speed: 3000 RPM

- feed rate: $5 \mathrm{~mm} / \mathrm{s}$

- cutting depth: $1 \mathrm{~mm}$

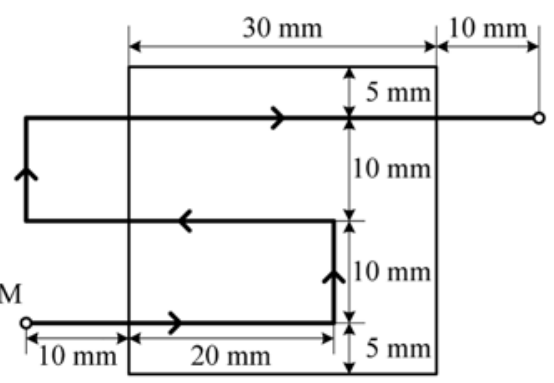

Fig. 6 Tool path and machining conditions used for the energy consumption simulation
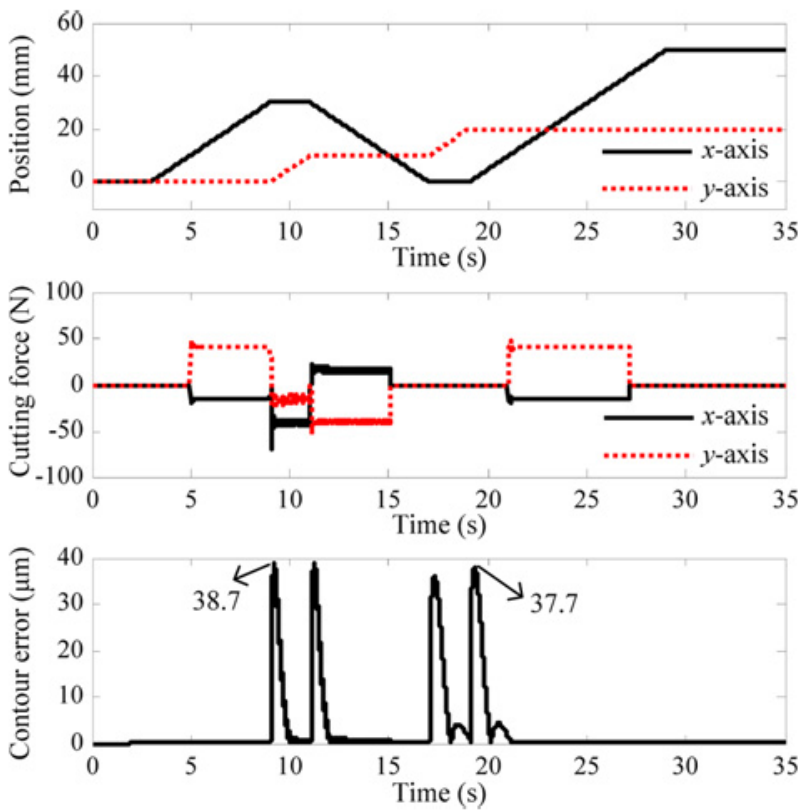

Fig. 7 Simulation results of the servo system dynamics: position and cutting forces of the $x$ - and $y$-axes, and contour error of the $x y$ table 
cutting torque applied to the spindle was less than $0.03 \mathrm{Nm}$. Table 5 shows the spindle motor parameters used in the simulation. To reduce the idling loss (energy loss during idling time), the lubricant pump was turned off except during material removal. Furthermore, the spindle speed was reduced simultaneously.

Fig. 9 shows the estimated power losses and energy consumptions of the machine tool components during milling. The loss of the spindle was
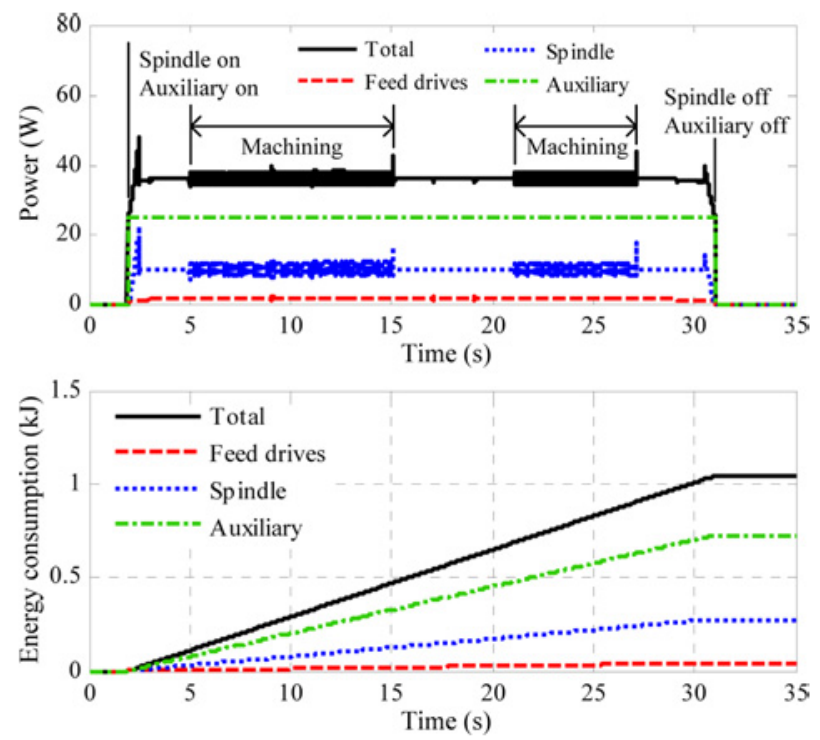

Fig. 8 Power losses and energy consumptions of machine tool components during milling

Table 5 Model parameters of the spindle motor

\begin{tabular}{ccc}
\hline Parameters (unit) & Spindle motor A & Spindle motor B \\
\hline$J_{M}\left(\mathrm{~kg} \mathrm{~m}^{2}\right)$ & $6.33 \times 10^{-5}$ & $4.43 \times 10^{-5}$ \\
\hline$k_{e 2}\left(\mathrm{~W} \mathrm{~s}^{2} / \mathrm{rad}^{2}\right)$ & $6.74 \times 10^{-2}$ & $4.71 \times 10^{-2}$ \\
\hline$k_{e l}(\mathrm{~W} \mathrm{~s} / \mathrm{rad})$ & $2.03 \times 10^{-4}$ & $1.42 \times 10^{-4}$ \\
\hline$k_{e 0}(\mathrm{~W})$ & $3.05 \times 10^{-2}$ & $2.14 \times 10^{-2}$ \\
\hline$D_{M}(\mathrm{Nm})$ & $3.66 \times 10^{-3}$ & $2.56 \times 10^{-3}$ \\
\hline$\mu_{v}(\mathrm{Nms})$ & $3.02 \times 10^{-5}$ & $2.13 \times 10^{-5}$ \\
\hline
\end{tabular}
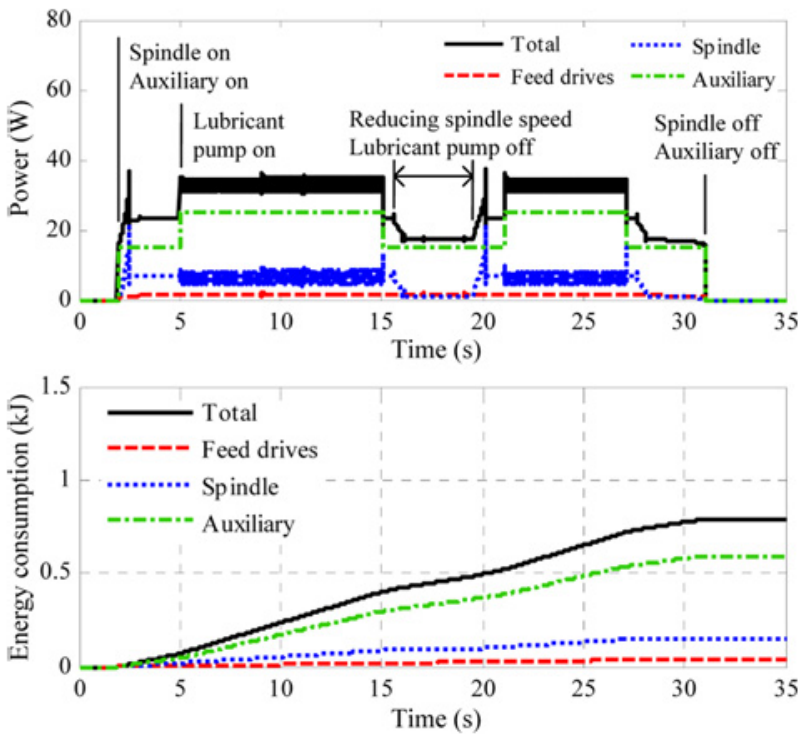

Fig. 9 Power losses and energy consumptions of machine tool components after applying the energy consumption reduction techniques decreased from 11.84 to $8.83 \mathrm{~W}$ during machining (loss estimated at $12 \mathrm{~s}$ ) as a result of the design modification. The idling loss of the spindle and auxiliary units (estimated at $17 \mathrm{~s}$ ) was reduced as a result of the process control.

Fig. 10 compares the energy consumption of the machine tool components. The energy consumption of the auxiliary and spindle units decreased from 0.73 to $0.60 \mathrm{~kJ}$ and from 0.27 to $0.15 \mathrm{~kJ}$, respectively. Consequently, the total energy consumption was reduced from 1.04 to $0.79 \mathrm{~kJ}$ as a result of the modifications to the machine tool design and process control.

Fig. 11 shows the relationship between the energy consumption and machining conditions simulated using the VMT. The specific energy (energy required for material removal) was simulated for MRRs from 1 to $10 \mathrm{~mm}^{3} / \mathrm{s}$ in steps of $1 \mathrm{~mm}^{3} / \mathrm{s}$. The MRR was varied by changing the feed rate; the spindle speed was also changed to maintain the chip load. The relationship between the SEC and the MRR can be expressed using the following equation: ${ }^{11}$

$$
S E C=\frac{37.5}{M R R}+3.008,
$$

where the constants 37.5 and 3.008 were derived by fitting the experimentally measured data. This equation can be used to determine the machining conditions considering the energy consumption.

Our proposed component-level model allowed us to estimate the specific energy consumption of a machine tool with a specific design configuration and process parameters and to profile the contribution of each component to energy consumption. The results can be used to select the appropriate machine tool components during the design stage and the appropriate process parameters during machining.

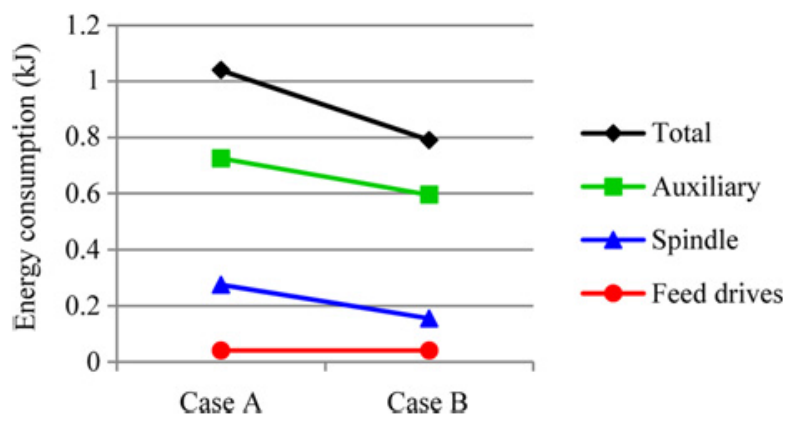

Fig. 10 Comparison of the energy consumption of the machine tool components before (case A) and after (case B) applying the energy consumption reduction techniques

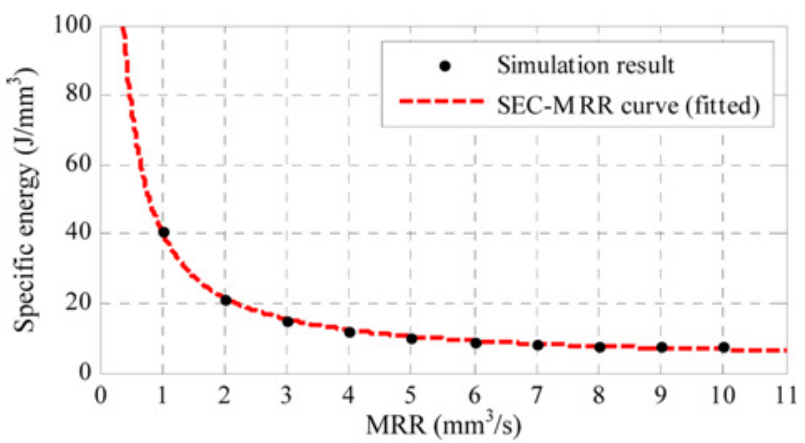

Fig. 11 Relationship between the specific energy and MRR 


\section{Conclusions}

A model for profiling the energy usage of a machine tool at the component level was proposed. This model focuses on estimating the dynamic behavior and energy consumption of the servo system, which has a major impact on the total energy consumption. An experimental testbed was built for the servo system to identify the necessary parameters and verify the model. The model was used to estimate the energy consumption of the feed drive components with an accuracy of $98.3 \%$. The energy consumption of a milling machine during machining was then simulated using a VMT. This technique was used to reduce the overall energy consumption and determine the relationship between the specific energy and the process parameters. The contribution of each component of the machine tool to its overall energy consumption was profiled.

\section{ACKNOWLEDGEMENT}

This work was supported by the Platform Technology Development program of the Ministry of Trade, Industry and Energy, Republic of Korea.

\section{REFERENCES}

1. Park, C.-W., Kwon, K.-S., Kim, W.-B., Min, B.-K., Park, S.-J., et al., "Energy Consumption Reduction Technology in Manufacturing - A Selective Review of Policies, Standards, and Research," Int. J. Precis. Eng. Manuf., Vol. 10, No. 5, pp. 151-173, 2009.

2. Dornfeld, D. A., "Moving Towards Green and Sustainable Manufacturing,” Int. J. Precis. Eng. Manuf.-Green Tech., Vol. 1, No. 1, pp. 63-66, 2014.

3. Ahn, S.-H., "An Evaluation of Green Manufacturing Technologies based on Research Databases," Int. J. Precis. Eng. Manuf.-Green Tech., Vol. 1, No. 1, pp. 5-9, 2014.

4. Kara, S., Bogdanski, G, and Li, W., "Electricity Metering and Monitoring in Manufacturing Systems," in: Glocalized Solutions for Sustainability in Manufacturing, Hesselbach, J. and Herrmann, C., (Ed.), Springer Berlin Heidelberg, pp. 1-10, 2011.

5. Behrendt, T., Zein, A., and Min, S., "Development of an Energy Consumption Monitoring Procedure for Machine Tools," CIRP Annals-Manufacturing Technology, Vol. 61, No. 1, pp. 43-46, 2012.

6. Pervaiz, S., Deiab, I., and Darras, B., "Power Consumption and Tool Wear Assessment When Machining Titanium Alloys," Int. J. Precis. Eng. Manuf., Vol. 14, No. 6, pp. 925-936, 2013.

7. Uhlmann, E., Eßmann, J., and Wintering, J.-H., "Design- and Control-Concept for Compliant Machine Tools based on Controller Integrated Models," CIRP Annals-Manufacturing Technology, Vol. 61, No. 1, pp. 347-350, 2012.

8. Okwudire, C. and Rodgers, J., "Design and Control of a Novel Hybrid Feed Drive for High Performance and Energy Efficient Machining," CIRP Annals-Manufacturing Technology, Vol. 62, No. 1, pp. 391-394, 2013.
9. Li, W., Zein, A., Kara, S., and Herrmann, C., "An Investigation into Fixed Energy Consumption of Machine Tools," Glocalized Solutions for Sustainability in Manufacturing, pp. 268-273, Springer, 2011.

10. Mori, M., Fujishima, M., Inamasu, Y., and Oda, Y., "A Study on Energy Efficiency Improvement for Machine Tools," CIRP AnnalsManufacturing Technology, Vol. 60, No. 1, pp. 145-148, 2011.

11. Diaz, N., Redelsheimer, E., and Domfeld, D., "Energy Consumption Characterization and Reduction Strategies for Milling Machine Tool Use," Glocalized Solutions for Sustainability in Manufacturing, Springer, pp. 263-267, 2011.

12. Park, Y.-J. and Lee, G.-B., "Analysis of Energy Efficiency and Productivity in Dry Process in PCB Manufacturing," Int. J. Precis. Eng. Manuf., Vol. 14, No. 7, pp. 1213-1221, 2013.

13. Denkena, B., Park, H.-S., Behrens, B.-A., Henjes, J., Bertys, S., et al., "Development of a Concept to Optimize the Energy Efficiency in Forging Process Chains," Int. J. Precis. Eng. Manuf., Vol. 14, No. 7, pp. 1229-1236, 2013.

14. Hermann, C., Thiede, S., Kara, S., and Hesselbach, J., "Energy Oriented Simulation of Manufacturing Systems - Concept and Application," CIRP Annals-Manufacturing Technology, Vol. 60, No. 1, pp. 45-48, 2011.

15. Jeong, Y. H., Min, B.-K., Cho, D.-W., and Lee, S. J., "Motor Current Prediction of a Machine Tool Feed Drive using a Component Based Simulation Model," Int. J. Precis. Eng. Manuf., Vol. 11, No. 4, pp. 597-606, 2010.

16. Altintas, Y. and Budak, E., "Analytical Prediction of Stability Lobes in Milling," CIRP Annals-Manufacturing Technology, Vol. 44, No. 1, pp. 357-362, 1995.

17. Canudas de Wit. C., Olsson, H., Astrom, K. J., and Lischinsky, P., "A New Model for Control of Systems with Friction," IEEE Transactions on Automatic Control, Vol. 40, No. 3, pp. 419-425, 1995.

18. Morimoto, S., Tong, Y., Takeda, Y., and Hirasa, T., "Loss Minimization Control of Permanent Magnet Synchronous Motor Drives," IEEE Transactions on Industrial Electronics, Vol. 41, No. 5, pp. 511-517, 1994.

19. Pritschow, G and Röck, S., "“Hardware in the Loop" Simulation of Machine Tools," CIRP Annals-Manufacturing Technology, Vol. 53, No. 1, pp. 295-298, 2004.

20. Landers, R. G., Min, B.-K., and Koren, Y., "Reconfigurable Machine Tools," CIRP Annals-Manufacturing Technology, Vol. 50, No. 1, pp. 269-274, 2001. 